FACULDADE DE TECNOLOGIA E CIÊNCIAS SOCIAIS APLICADAS FATECS

PROGRAMA DE INICIAÇÃO CIENTÍFICA

EVERTON BORGHETTI

ANÁLISE DE DIFERENTES PROPOSTAS DE LONGARINAS EM PONTES DE CONCRETO ARMADO ATRAVÉS DA FERRAMENTA SAP 2000 


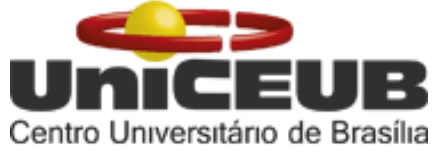

EVERTON BORGHETTI

\section{ANÁLISE DE DIFERENTES PROPOSTAS DE LONGARINAS EM PONTES DE CONCRETO ARMADO ATRAVÉS DA FERRAMENTA SAP 2000}

Relatório final de pesquisa de Iniciação
Científica apresentado à Assessoria de Pós-
Graduação e Pesquisa pela Faculdade de
Tecnologia e Ciências Sociais Aplicadas -
FATECS
Orientação: Rosanna Duarte Fernandes Dutra

BRASÍLIA-DF

2016 


\section{ANÁLISE DE DIFERENTES PROPOSTAS DE LONGARINAS EM PONTES DE CONCRETO ARMADO ATRAVÉS DA FERRAMENTA SAP2000}

Everton Borghetti - UniCEUB, PIC Institucional, aluno bolsista everton.borghetti@hotmail.com

Rosanna Duarte Fernandes Dutra - UniCEUB, Professora orientadora rosanna.dutra@uniceub.br

Este trabalho tem como objetivo a apresentação de uma proposta para o dimensionamento de longarinas de pontes de concreto armado convencional com nove ou cinco vigas longarinas. Para obtenção dos momentos fletores sobre as vigas utilizou-se o software de elementos finitos. Foi realizado um levantamento sobre os tipos de carregamentos em pontes e considerações que se devem fazer antes de sua concepção, a partir da situação proposta de pontes em concreto armado com nove ou cinco vigas principais. As vigas foram tratadas como vigas $\mathrm{T}$, considerando a contribuição da laje do tabuleiro.

Palavras - Chave: Pontes; Longarinas; Softwares 


\section{SUMÁRIO}

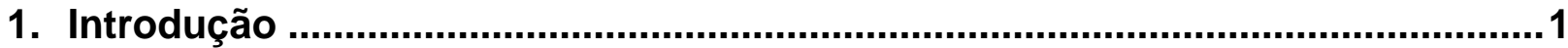

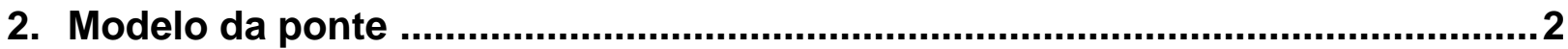

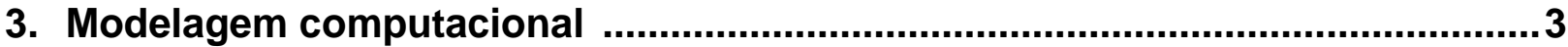

4. Distribuição do carregamento da ponte ..........................................................

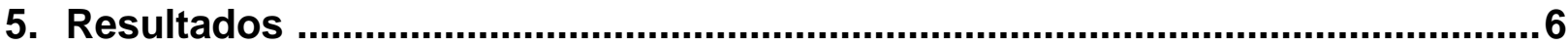

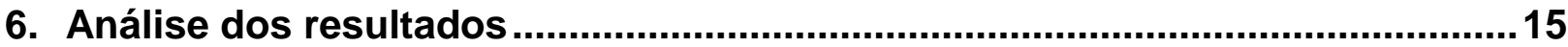

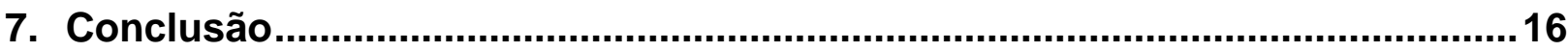

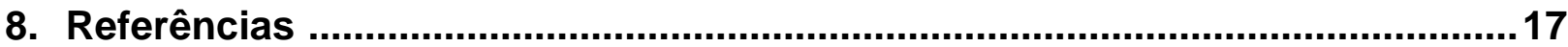




\section{FIGURAS}

Figura 1. Projeto da ponte, vista lateral

Figura 2. Seção transversal típica da ponte em estudo ........................................................3

Figura 3. Ilustração esquematizada do modelo 3D utilizado ..................................................4

Figura 4. Carregamento previsto para o veículo descrito....................................................6

Figura 5. Diagrama do momento fletor da estrutura com 9 longarinas, considerando peso próprio e sobrecarga permanente

Figura 6. Diagrama de esforço cortante da estrutura com 9 longarinas, considerando peso próprio e sobrecarga permanente

Figura 7. Diagrama de esforço de torção da estrutura com 9 longarinas, considerando peso próprio e sobrecarga permanente

Figura 8. Diagrama do momento fletor da estrutura com 9 longarinas, considerando a carga móvel

Figura 9. Diagrama de esforço Cortante da estrutura com 9 longarinas, considerando a carga móvel

Figura 10. Diagrama de esforço de torção da estrutura com 9 longarinas, considerando a carga móvel.

Figura 11. Primeiro modo de vibração: Deslocamentos de verticais da estrutura .............9

Figura 12. Segundo Modo de vibração: Deslocamentos de verticais da estrutura em

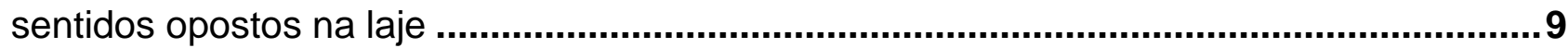

Figura 13. Terceiro modo de vibração: Deslocamentos verticais da estrutura ....................9

Figura 14. Quarto modo de vibração: Deslocamentos de verticais e horizontais da estrutura

Figura 15. Quinto modo de vibração: Deslocamentos de verticais e horizontais da estrutura

Figura 16. Indicação das vigas longarinas retiradas

Figura 17. Diagrama do momento fletor da estrutura com 5 longarinas, considerando peso próprio e sobrecarga permanente

Figura 18. Diagrama de esforço cortante da estrutura com 5 longarinas, considerando peso próprio e sobrecarga permanente.

Figura 19. Diagrama de esforço de torção da estrutura com 5 longarinas, considerando peso próprio e sobrecarga permanente

Figura 20. Diagrama do momento fletor da estrutura com 5 longarinas, considerando a carga móvel.

Figura 21. Diagrama de esforço cortante da estrutura com 5 longarinas, considerando a carga móvel

Figura 22. Diagrama de esforço de torção da estrutura com 5 longarinas, considerando peso próprio e sobrecarga permanente

Figura 23. Primeiro modo de vibração: Deslocamentos de verticais da estrutura

Figura 24. Segundo modo de vibração: Deslocamentos de verticais da estrutura em sentidos opostos na laje 
Figura 25. Terceiro modo de vibração: Deslocamentos de verticais da estrutura .14

Figura 26. Quarto modo de vibração: Deslocamentos de verticais e horizontais da

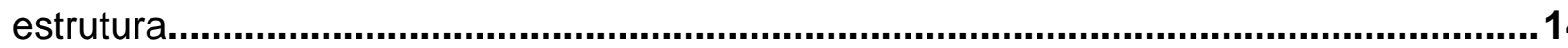

Figura 27. Quinto modo de vibração: Deslocamentos horizontais da estrutura

\section{TABELAS}

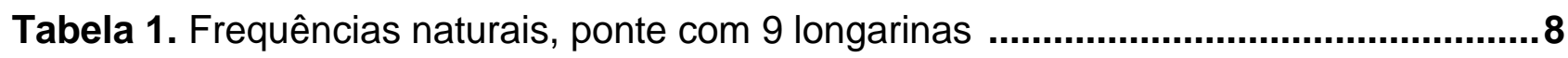

Tabela 2. Frequências naturais, ponte com 5 longarinas ..............................................12

Tabela 3. Comparação dos esforços solicitados entre as duas estruturas, considerando peso próprio e sobrecarga permanente 15

Tabela 4. Comparação dos esforços solicitados entre as duas estruturas, considerando carga móvel .15

Tabela 5. Comparação da frequência natural nas duas estruturas .15 


\section{INTRODUÇÃO}

Obras de arte, pontes e viadutos, podem possuir grandes vãos a serem transpostos e por consequente grandes dimensões, há ainda obras menores, onde também se aplicam os conceitos aqui expostos, assim um bom projeto acarretará em economia, segurança, durabilidade, vida útil e modernamente robustez. Desta forma procurou-se utilizar-se de conceitos já amplamente empregados e normatizados com a NBR 6118:2003 para dimensionamentos.

Visando maior simplicidade construtiva e consequente redução de custos, há uma tendência crescente na supressão de elementos estruturais de grande importância para as pontes. Esse tipo de simplificação, entretanto, quando ocorrem longarinas intermediárias, não permite que se tire proveito da ação combinada destes elementos e da laje do tabuleiro na distribuição transversal da carga móvel, além de reduzir a rigidez da estrutura e, portanto, torná-la mais deformável.

Para este trabalho serão consideradas pontes em concreto armado de uso rodoviário, com vigas, sendo sempre em número de duas longarinas sendo sempre de altura constante, sabendo que: "A viga é o tipo mais simples de estrutura, sendo adequada para uma extensa faixa de variação de vãos, desde 10 metros, nos pontilhões de concreto armado, até mais de 100 metros, em vigas protendidas de altura variável" (DNER, 1996). Segundo Spernau (2013), constituem o sistema principal da superestrutura, daí chamarem-se vigas principais. Recebem todas as cargas da superestrutura, conduzindoas à mesoestrutura. Podem assumir formas diversas de acordo com as características da ponte (vão e largura do tabuleiro).

Ainda segundo DNER (1996), "as estruturas em vigas requerem detalhes de moldagem e de acabamento mais trabalhosos que as estruturas em laje maciça ou vazada, implicando em tempo de construção mais longo e em custo adicional; por outro lado, é possível obter-se soluções mais econômicas através da escolha criteriosa das vigas. A comparação entre os custos de construção das vigas e o da espessura adicional da laje será determinante na escolha da forma estrutural."

Desta forma busca-se através de processo de modelagem numérica em softwares comerciais a verificação de diversas possibilidades de posicionamento dos elementos 
constituintes da superestrutura e suas proporções, tais como laje do tabuleiro, balanços transversais e longitudinais e dimensões das vigas principais. Dessa forma, pretende-se, a partir de vários resultados, escolher um que atenda melhor as exigências de forma possivelmente mais econômica.

\section{MODELO DA PONTE}

O viaduto de 40,00 m de comprimento, composto de 25,0 m entre apoios e 2×5,50 de balanços, e 23,40 m de largura. A estrutura, cujo vão típico está representado na figura 1, foi dimensionada para a ação do trem-tipo Classe $450 \mathrm{kN}$, conforme item 3.5 da NBR $7188 / 84$. Todo o estudo referente ao material concreto armado seguiu as prescrições da norma brasileira NBR 6118:2014 (Projeto de estruturas de concreto - Procedimento).

A superestrutura possui vigas com comprimento de $25,0 \mathrm{~m}$ divididos em dois balanços de 5,50m e um vão central de 29,0m (distância entre centro de neoprenes de apoio restrições de apoio). O tabuleiro será considerado simétrico. O tabuleiro é constituído de:

- 9 longarinas (representadas por elementos de barra);

- Elementos finitos que dividem as 9 longarinas, conforme indicado na figura.

- Transversinas nos apoios e no vão (representadas por elementos de barra);

- Largura do tabuleiro (laje) é de 23,40 m.

\section{CORIE LONGIIDINLL} ESG.1:100

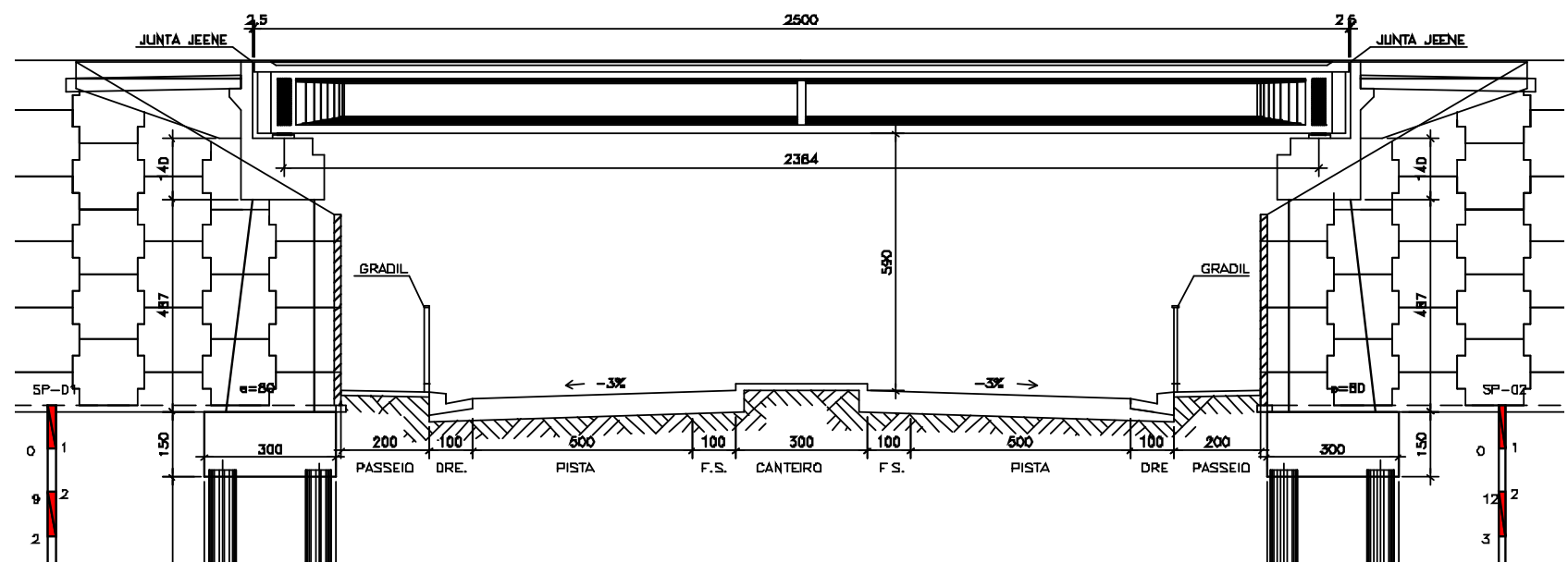

Figura 1. Projeto da ponte, vista lateral. 


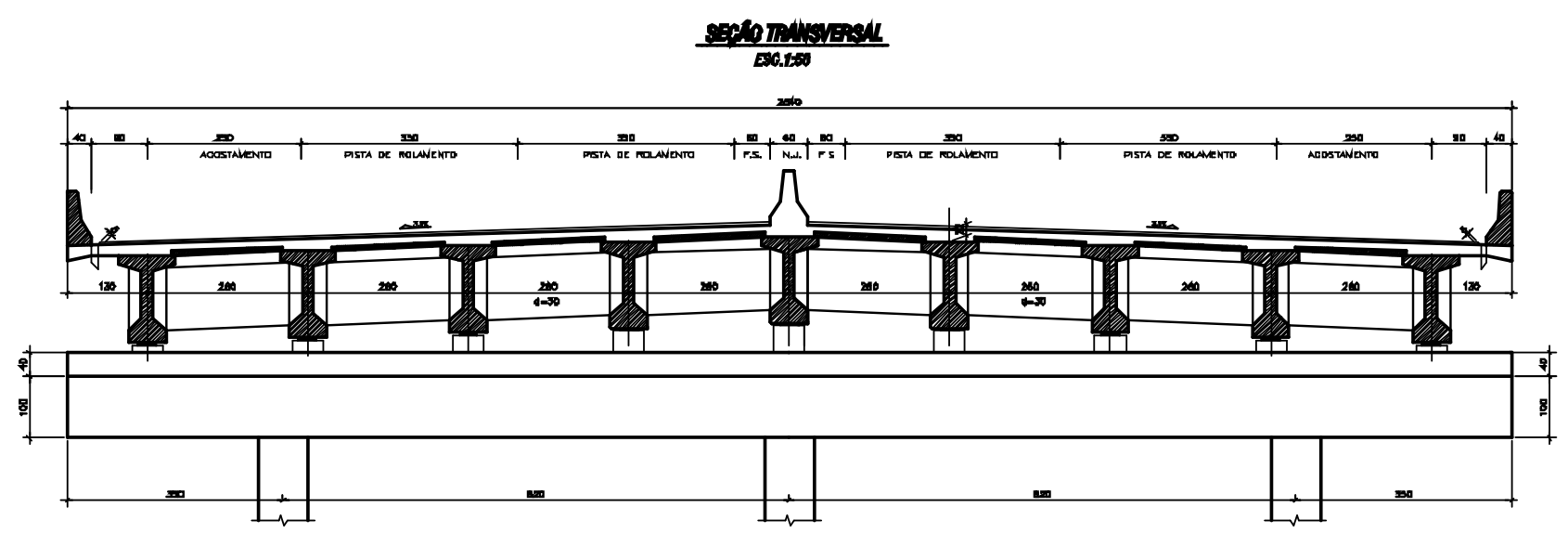

Figura 2. Seção transversal típica da ponte em estudo.

\section{MODELAGEM COMPUTACIONAL}

\subsection{Software SAP2000}

A sigla S.A.P. é a abreviação de Structural Analysis Program e pertence à família de softwares para estruturas mais usada no mundo para Análise Estrutural, por meio dele pode-se analisar e projetar uma estrutura desejada utilizando uma interface gráfica de fácil aplicação.

O programa utiliza para seus cálculos o processo de subdivisão da estrutura por elementos finitos, ou seja, ele discretiza a estrutura em pequenas regiões (pontos) onde se efetuam os cálculos. A precisão dos resultados varia de acordo com o número de elementos finitos que a estrutura é discretizada, ou seja, quanto maior o número de discretizações, maior será o resultado, sendo que o programa possibilita essa manipulação.

Para efeito da análise, foi adotado para o concreto as seguintes características físicas: fck de 25Mpa para superestrutura, meso e infra, e fck de 20 Mpa para a laje de transição, módulo de elasticidade igual a 30,1GPa e coeficiente de Poisson igual a 0,2, aço comum CA-50. 

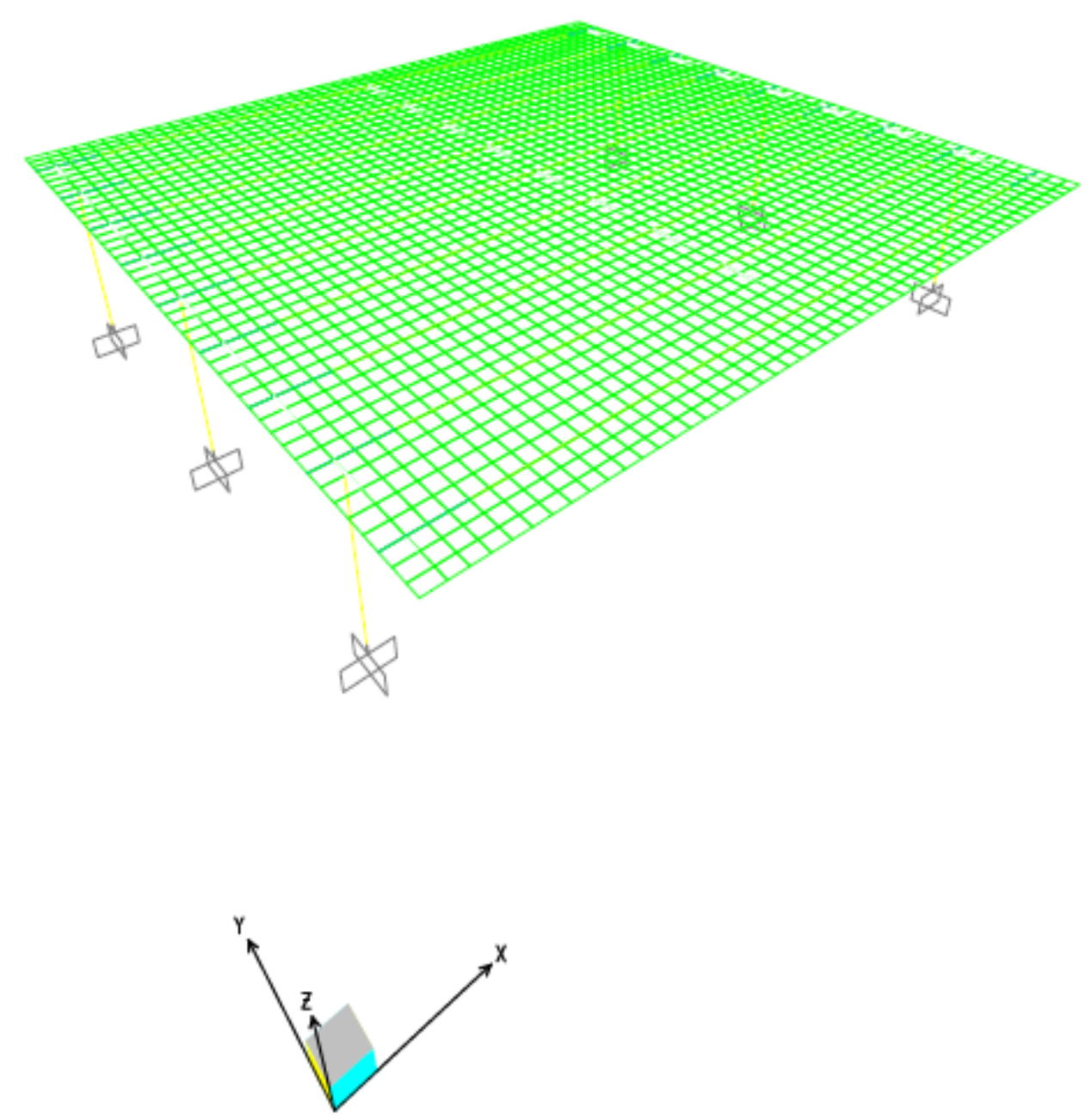

Figura 3. Ilustração esquematizada do modelo 3D utilizado.

O modelo 3D aqui desenvolvido representa melhor o comportamento da estrutura ao simular o funcionamento do conjunto laje, longarinas e transversinas, levando em conta a excentricidade existente entre os elementos estruturais. A modelagem da laje como elemento de casca e seu funcionamento como mesa de compressão originam esforços de membrana na direção longitudinal do tabuleiro, ou seja, esforços normais distribuídos ao longo da largura da laje. Nas longarinas, modeladas como elementos de barra, além dos momentos fletores surgem esforços normais.

\section{DISTRIBUIÇÃO DOS CARREGAMENTOS VERTICAIS NA PONTE}

\subsection{Peso Próprio}

Para o peso próprio dos elementos constituintes da estrutura da ponte, tais como vigas longarinas, vigas transversinas e tabuleiro, foi adotado peso específico do concreto armado igual a $25,00 \mathrm{kN} / \mathrm{m}^{3}$. Definimos como carregamento permanente as seguintes cargas: 
- Vigas + lajes + transversinas + cortinas e alas $=g 1$

- Laje de transição = g2

- Barreiras e pavimento $=g 3$

\subsection{Pavimentação}

Foi adotado carregamento devido à pavimentação igual a $2,00 \mathrm{kN} / \mathrm{m}^{2}$, de acordo com a norma brasileira NBR 7187:2003 (Projeto de pontes de concreto armado e de concreto protendido - Procedimento). O carregamento foi lançado em todo o tabuleiro da ponte.

\subsection{Guarda-rodas}

A carga devido aos guarda-rodas da ponte foi considerada igual a $5,00 \mathrm{kN} / \mathrm{m}^{2} \mathrm{e}$ lançada nas posições ocupadas por eles.

\subsection{Carga Móvel}

O trem-tipo utilizado foi o TB 45. Este foi adotado seguindo as prescrições da norma brasileira NBR 7188:1984 (Carga móvel em ponte rodoviária e passarela de pedestre). O valor 45 é referente ao peso total do veículo padrão utilizado e é equivalente a 450,00 kN. Em cada roda é aplicada uma força de 75,00 kN. Feitas as seguintes considerações de cálculo:

- $\quad$ Coeficiente de impacto (consideraremos, a favor da segurança, $I=2 \times I_{b}$ ):

$>\varphi=1,4-0,007 \times(2 \times 5,5)=1,323$

- $\quad$ Multidão (q):

$$
q=0,5 \times 1,323=0,6615 \mathrm{tt} / \mathrm{m}^{2}
$$

- Veículo:

$$
\text { > } \mathrm{Q}=\frac{45}{6} \times 1,323=9,92 \mathrm{t} / \mathrm{roda}
$$

- Consideraremos esta carga da roda distribuída até o eixo da laje.

- Dimensões da roda $20 \times 50 \mathrm{~cm}$.

- Pavimento + metade da espessura da laje $=25 \mathrm{~cm}$

- Desta forma temos uma área de distribuição de $20+2 \times 25=70 \mathrm{~cm}$ e $50+2 \times$ $25=100 \mathrm{~cm}$

- $\quad$ Carga da roda $\mathrm{c} /$ impacto $=9,92 /(0,70 \times 1,00)=14,17 \mathrm{tf} / \mathrm{m}^{2}$ 
- $\quad$ Além da carga acima descrita foi prevista uma carga uniformemente distribuída na projeção do veículo de $+0,6615 \mathrm{tt} / \mathrm{m}^{2}$. Este carregamento teve sinal positivo (contrário ao da multidão). A figura a seguir apresenta o carregamento previsto para o veículo anteriormente descrito.

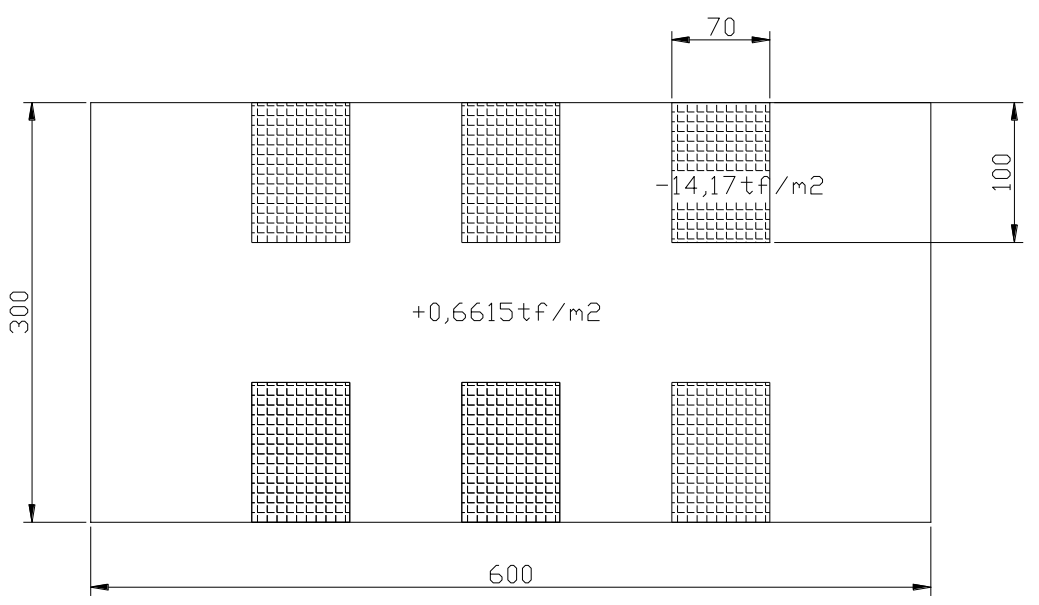

Figure 4. Carregamento previsto para o veículo descrito.

\subsection{Vento}

O cálculo da carga devido à ação do vento foi obtido de acordo com a norma brasileira NBR 6123:1988 (Forças devidas ao vento em edificações).

\subsection{Sobrecarga de multidão}

A sobrecarga de multidão adotada foi $5,00 \mathrm{kN} / \mathrm{m}^{2}$ de acordo com a norma brasileira NBR 7188:1984 (Carga móvel em ponte rodoviária e passarela de pedestre).

\subsection{Frenagem}

O valor da carga devido à frenagem foi considerado igual a $30 \%$ do valor do peso do trem-tipo adotado, de acordo com a norma brasileira NBR 7187:2003 (Projeto de pontes de concreto armado e de concreto protendido - Procedimento). Como o tremtipo adotado foi o TB 45, a força de frenagem adotada foi igual a $135,00 \mathrm{kN}$ e aplicada na direção longitudinal à ponte.

\section{RESULTADOS}

\subsection{Resultado dos esforços da estrutura com 9 vigas longarinas}

Abaixo a seção analisada para retirada dos valores de esforços de uma das vigas principais, a primeira viga observada na planta da figura 1. 


\subsubsection{Diagramas considerando peso próprio e sobrecarga permanente}

Os momentos fletores, os esforços cortantes e torções encontrados para o modelo com transversinas, considerando o peso próprio juntamente com a sobrecarga permanente da estrutura, estão esquematizados nos diagramas abaixo.

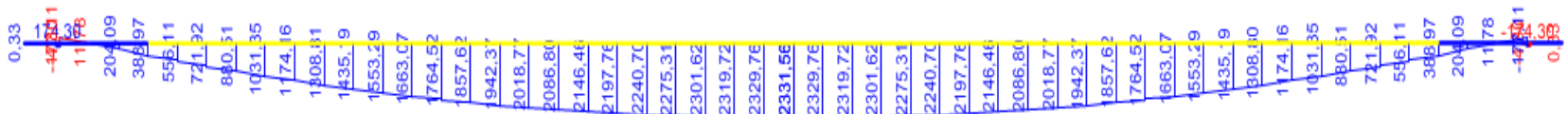

Figura 5. Diagrama do momento fletor da estrutura com 9 longarinas, considerando peso próprio e sobrecarga permanente.

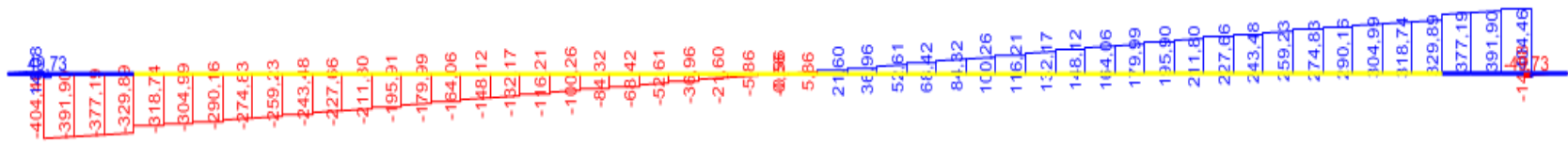

Figura 6. Diagrama de esforço cortante da estrutura com 9 longarinas, considerando peso próprio e sobrecarga permanente.

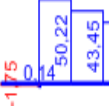

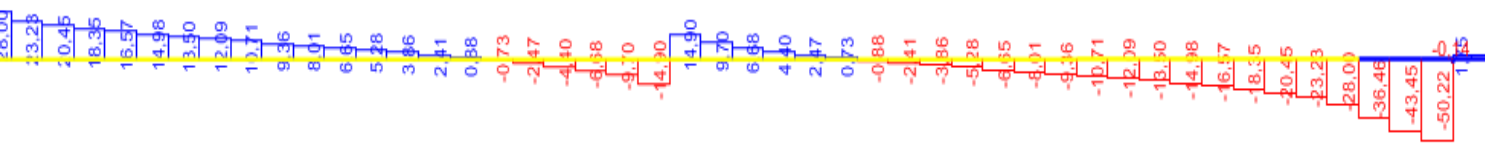

Figura 7. Diagrama de esforço de torção da estrutura com 9 longarinas, considerando peso próprio e sobrecarga permanente.

O maior momento identificado foi de $2331,58 \mathrm{KN} \cdot \mathrm{m}$, o maior esforço cortante foi de $404 \mathrm{KN}$ e o maior esforço torçor foi de $50,22 \mathrm{KN} \cdot \mathrm{m}$.

\subsubsection{Diagramas considerando a carga móvel}

Os momentos fletores, os esforços cortantes e torções encontrados para o modelo com transversinas considerando a carga móvel da estrutura estão listados abaixo:

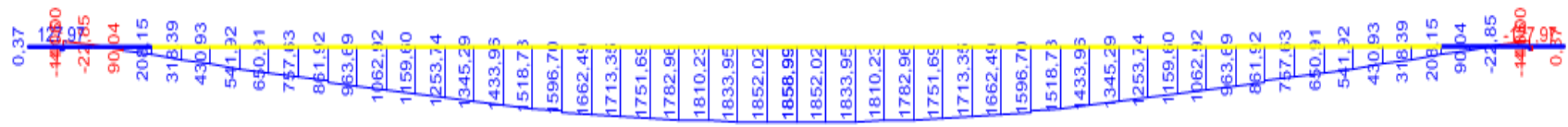

Figure 8. Diagrama do momento fletor da estrutura com 9 longarinas, considerando a carga móvel. 
\$ 33.32

Figure 9. Diagrama de esforço cortante da estrutura com 9 longarinas, considerando a carga móvel.

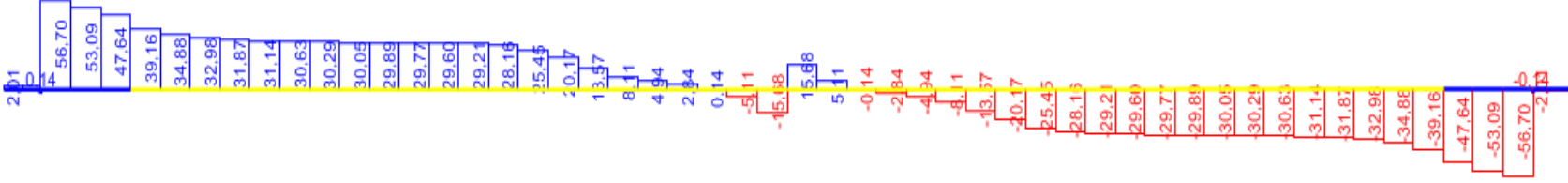

Figure 10. Diagrama de esforço de torção da estrutura com 9 longarinas, considerando a carga móvel.

O momento maior identificado foi de $1858,99 \mathrm{KN} \cdot \mathrm{m}$, o maior esforço cortante foi de $237,85 \mathrm{KN}$ e o maio esforço torçor foi de $56,70 \mathrm{KN} \cdot \mathrm{m}$.

\subsubsection{Análise dinâmica do Carregamento da ponte com 9 vigas longarinas}

As análises dinâmicas foram realizadas com base num modelo numérico de elementos finitos, tridimensional, desenvolvido no software SAP 2000 V.15. O modelo dinâmico da ponte foi baseado em parâmetros modais, de frequência de vibração e configurações modais, obtidos por meio da análise modal no SAP. As condições verificadas foram: modos de vibração para flexão vertical e torção e frequências naturais dos elementos:

Com a análise modal, os cinco primeiros modos de vibração obtidos foram os seguintes:

\begin{tabular}{|c|c|}
\hline Modo & Frequências $(\mathrm{Hz})$ \\
\hline 1 & 3,20914 \\
\hline 2 & 3,37109 \\
\hline 3 & 4,20523 \\
\hline 4 & 4,69027 \\
\hline 5 & 5,9675 \\
\hline
\end{tabular}

Tabela 1. Frequências naturais, ponte com 9 longarinas 
Nas figuras abaixo tem-se as deformação geradas pelos respectivos modos de vibração. Observando que a parte na cor cinza corresponde a estrutura original.

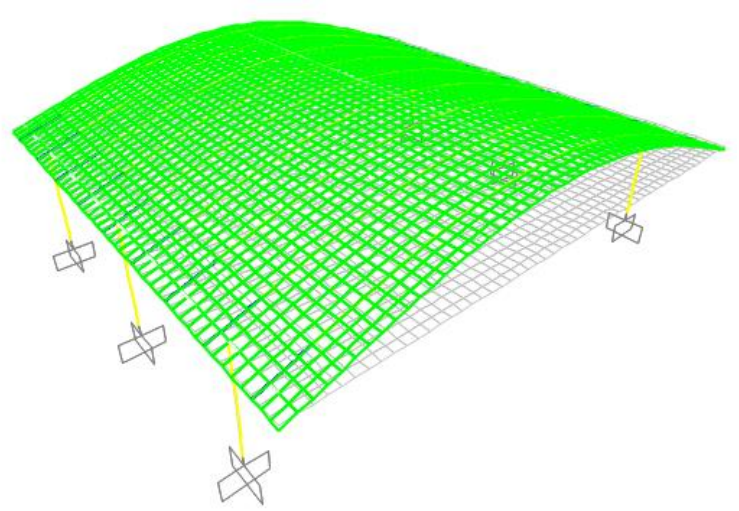

Figura 11. Primeiro modo de vibração: Deslocamentos de verticais da estrutura.

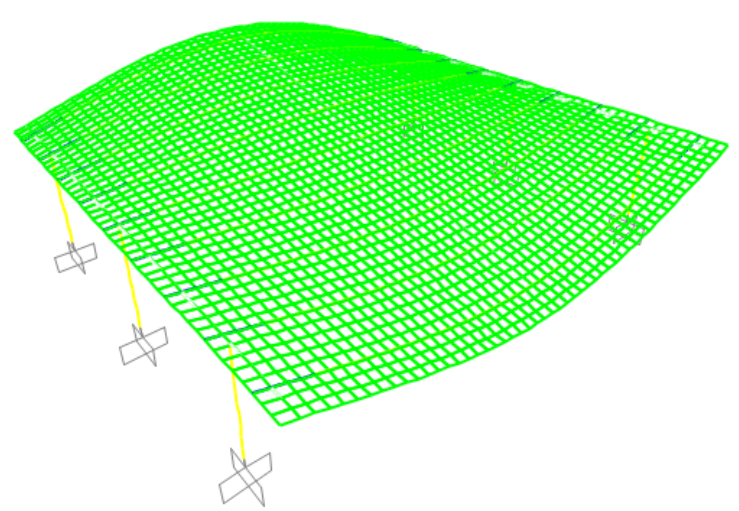

Figura 12. Segundo modo de vibração: Deslocamentos de verticais da estrutura em sentidos opostos na laje.

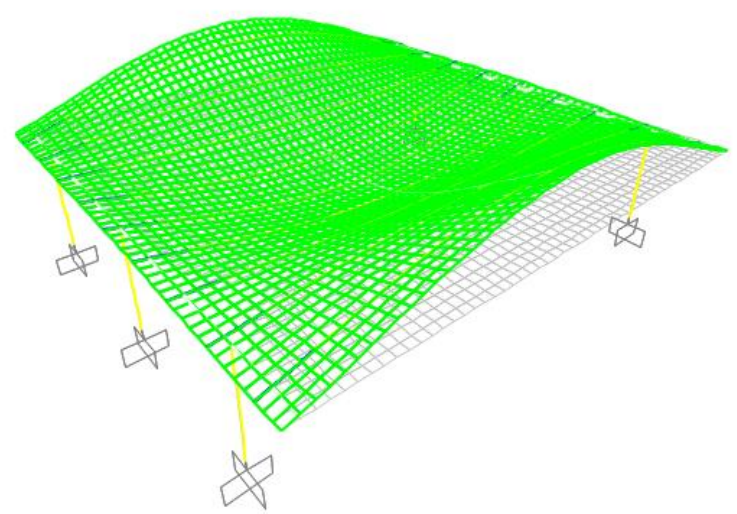

Figura 13. Terceiro modo de vibração: Deslocamentos verticais da estrutura. 


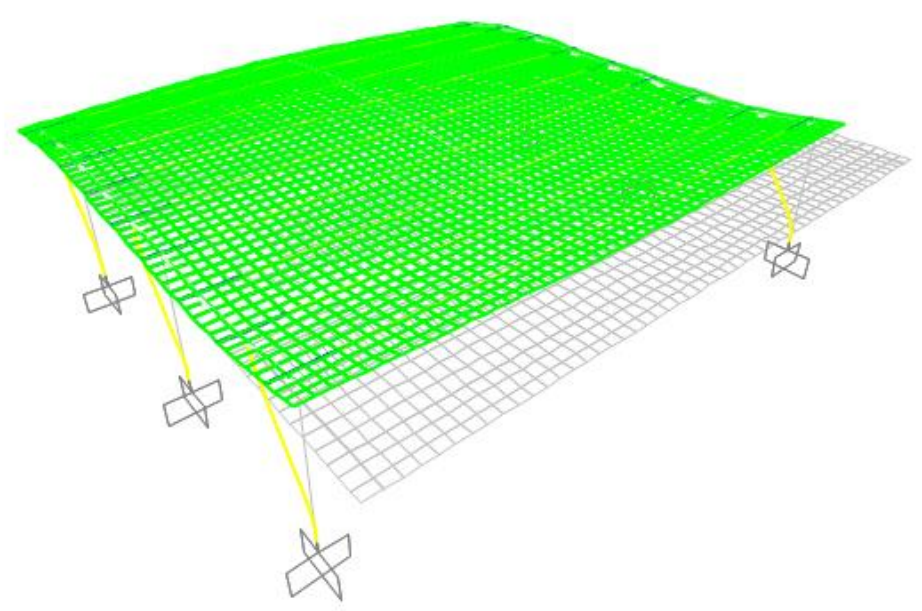

Figura 14. Quarto modo de vibração: Deslocamentos de verticais e horizontais da estrutura.

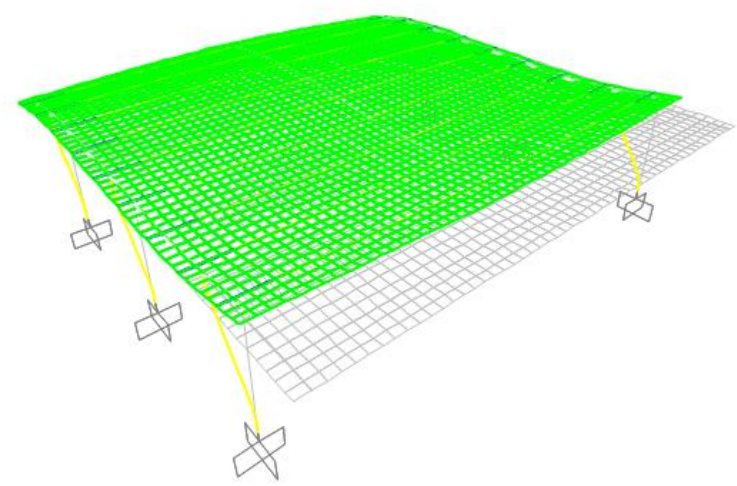

Figura 15. Quinto modo de vibração: Deslocamentos de verticais e horizontais da estrutura.

\subsection{Resultados dos esforços da estrutura com 5 vigas longarinas}

Abaixo a figura representa as vigas longarinas que serão retiradas do modelo principal da ponte e a relação de resultados referente a estudo.

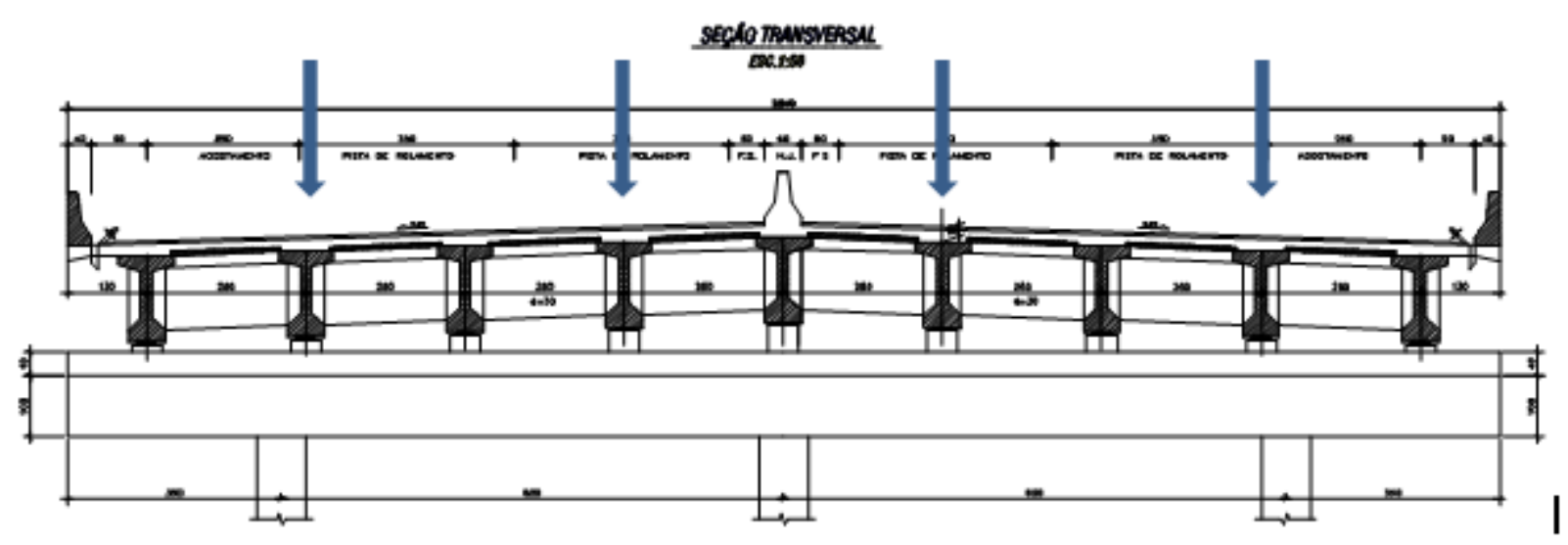

Figura 16. Indicação das vigas longarinas retiradas. 


\subsubsection{Diagramas considerando peso próprio e sobrecarga permanente}

Os momentos fletores, os esforços cortantes e torções encontrados para o modelo com transversinas considerando o peso próprio juntamente com a sobrecarga permanente da estrutura estão listados abaixo:

\section{H4h}

Figure 17. Diagrama do momento fletor da estrutura com 5 longarinas, considerando peso próprio e sobrecarga permanente.

$\stackrel{8}{0.45}$

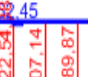

Figure 18. Diagrama de esforço cortante da estrutura com 5 longarinas, considerando peso próprio e sobrecarga permanente.

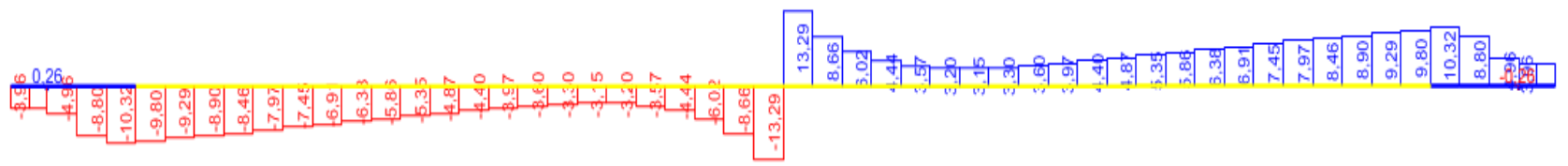

Figure 19. Diagrama de esforço de torção da estrutura com 5 longarinas, considerando peso próprio e sobrecarga permanente.

O momento maior identificado foi de $3162,64 \mathrm{KN} \cdot \mathrm{m}$, o maior esforço cortante foi de $522 \mathrm{KN}$ e o maio esforço torçor foi de $13,29 \mathrm{KN} \cdot \mathrm{m}$.

\subsubsection{Diagramas considerando a carga móvel}

Os momentos fletores, os esforços cortantes e torções encontrados para o modelo com transversinas considerando a carga móvel da estrutura estão listados abaixo:

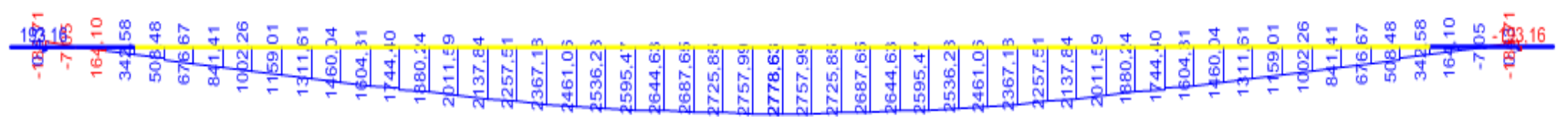

Figure 20. Diagrama do momento fletor da estrutura com 5 longarinas, considerando a carga móvel. 
Figure 21. Diagrama de esforço cortante da estrutura com 5 longarinas, considerando a carga móvel.

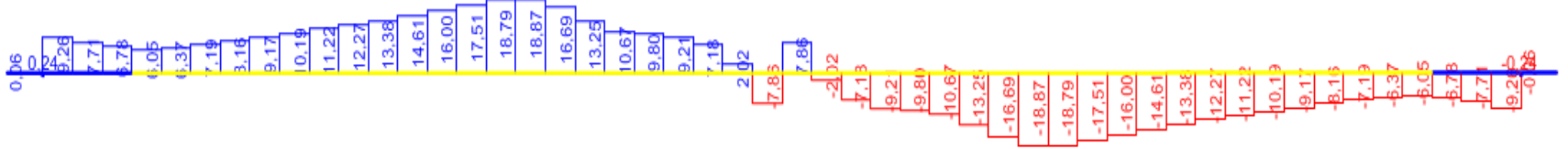

Figure 22. Diagrama de esforço de torção da estrutura com 5 longarinas, considerando peso próprio e sobrecarga permanente.

O momento maior identificado foi de $2778 \mathrm{KN} \cdot \mathrm{m}$, o maior esforço cortante foi de $361,80 \mathrm{KN}$ e o maio esforço torçor foi de $18,79 \mathrm{KN} \cdot \mathrm{m}$.

\subsubsection{Análise dinâmica do carregamento da ponte com 5 vigas longarinas}

As análises dinâmicas foram realizadas com base num modelo numérico de elementos finitos, tridimensional, desenvolvido no software SAP 2000 V.15. O modelo dinâmico da ponte foi baseado em parâmetros modais, de frequência de vibração obtido por meio da análise no SAP. As condições verificadas foram: modos de vibração para flexão vertical e frequências naturais dos elementos:

Com a análise modal, os cinco primeiros modos de vibração obtidos foram os seguintes:

\begin{tabular}{|c|c|}
\hline Modo & Frequências $(\mathbf{H z})$ \\
\hline 1 & 2,68729 \\
\hline 2 & 2,99636 \\
\hline 3 & 3,97972 \\
\hline 4 & 5,01218 \\
\hline 5 & 6,28708 \\
\hline
\end{tabular}

Tabela 2. Frequências naturais, ponte com 5 longarinas. 
Nas figuras abaixo estão ilustradas as deformações geradas pelos respectivos modos de vibração. Observando que a parte na cor cinza corresponde a estrutura original.

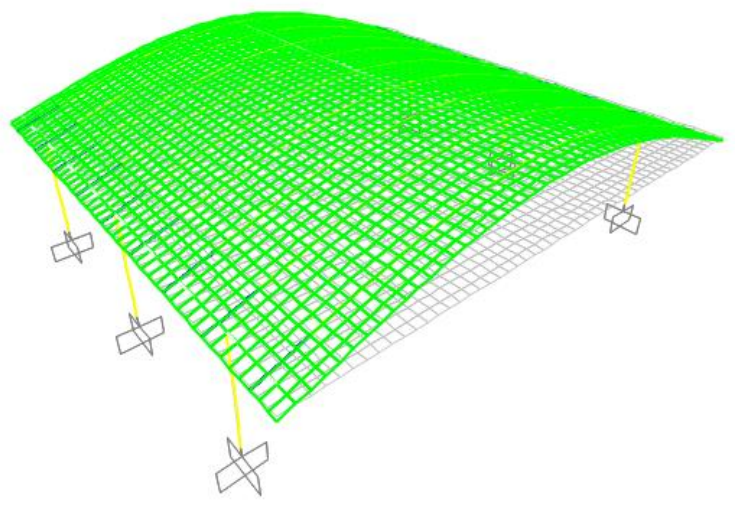

Figura 23. Primeiro modo de vibração: Deslocamentos de verticais da estrutura.

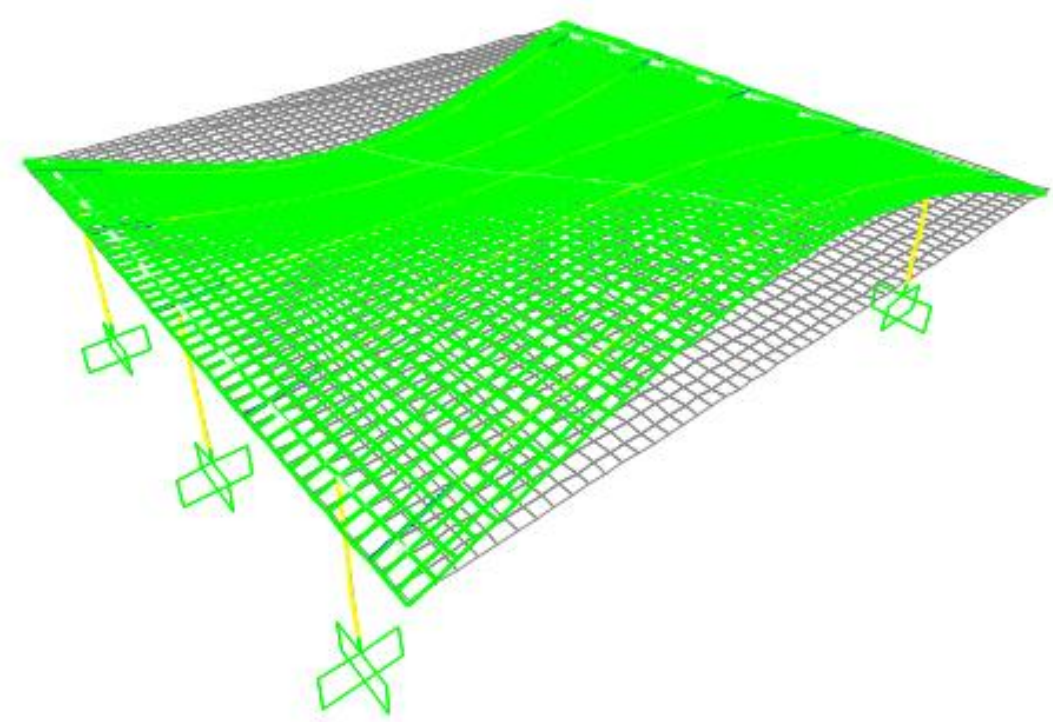

Figure 24. Segundo modo de vibração: Deslocamentos de verticais da estrutura em sentidos opostos na laje. 


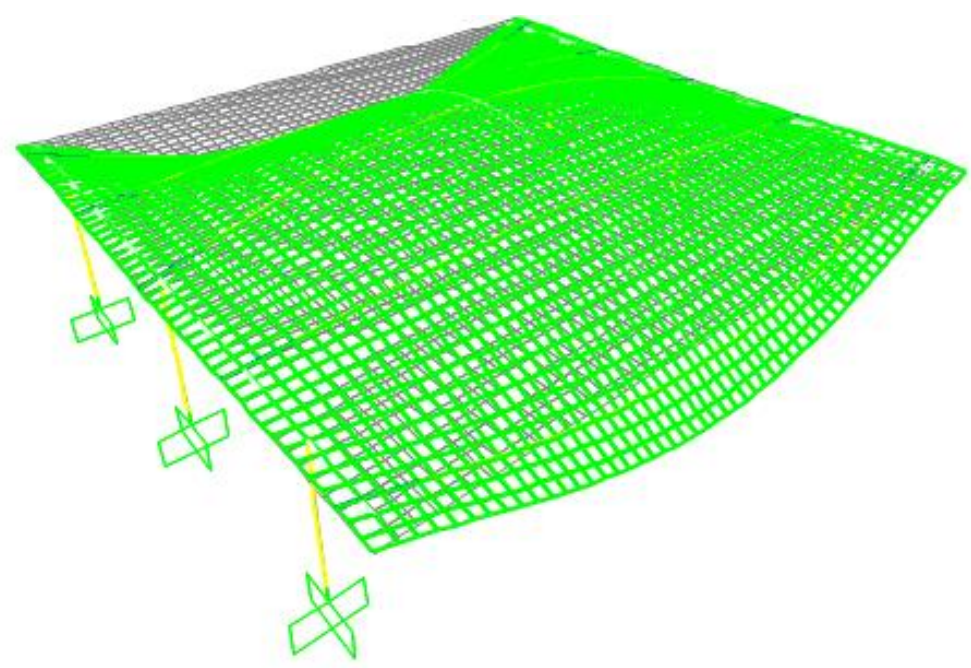

Figure 25. Terceiro modo de vibração: Deslocamentos de verticais da estrutura.

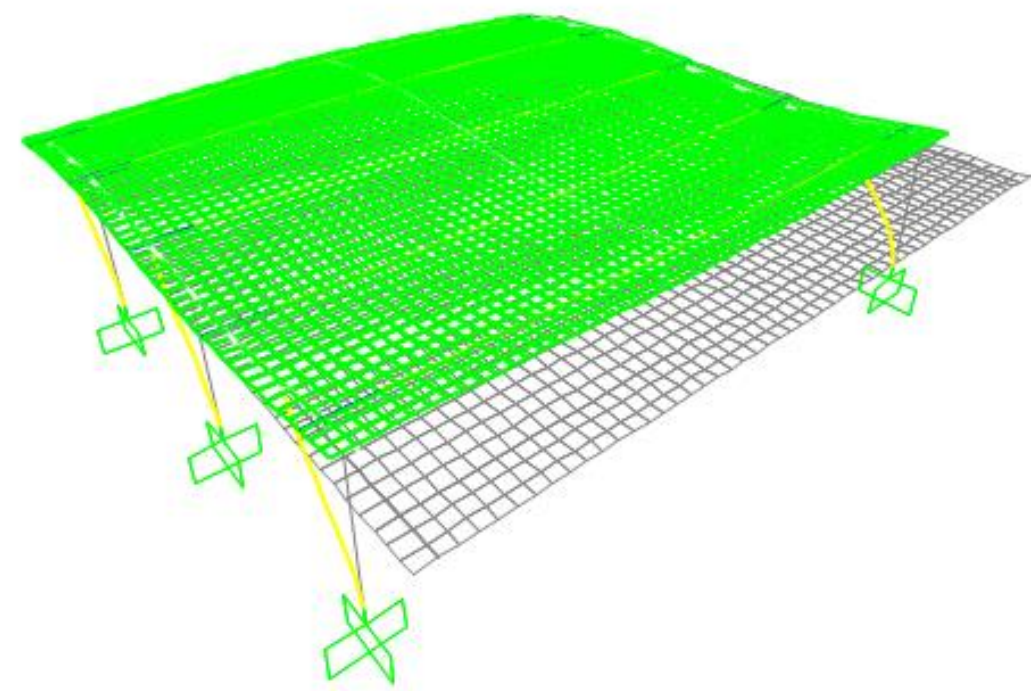

Figure 26. Quarto modo de vibração: Deslocamentos de verticais e horizontais da estrutura.

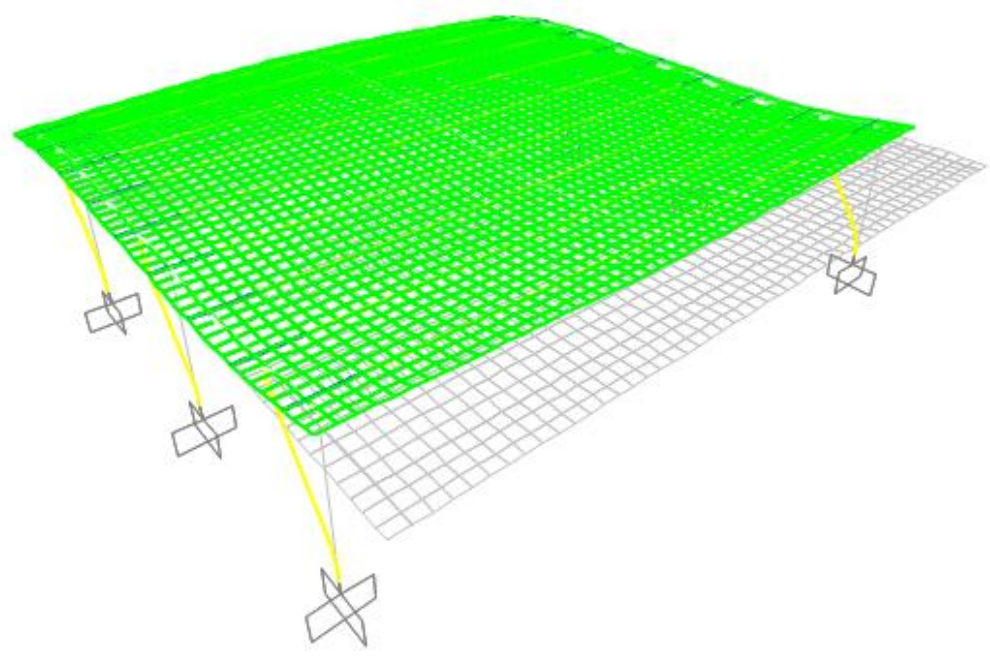

Figure 27. Quinto modo de vibração: Deslocamentos horizontais da estrutura. 


\section{ANÁLISE DOS RESULTADOS}

A tabela a seguir relaciona a estrutura constituinte de nove vigas longarinas principais com uma estrutura similar, onde foram retiradas 4 vigas longarinas, levando em consideração momento fletor, esforço cortante e esforço torçor, para o carregamento do peso próprio e a sobrecarga permanente.

\begin{tabular}{|c|c|c|}
\hline \multicolumn{3}{|c|}{ VALORES CONSIDERANDO PESO PRÓPRIO E SOBRECARGA PERMANETE } \\
\hline & Ponte com 9 longarinas & Ponte com 5 longarinas \\
\hline Momentos fletores (KN.m) & 2331,58 & 3162,64 \\
\hline Esforços cortantes $(\mathrm{KN})$ & 404,00 & 522,00 \\
\hline Esforço de torção $(\mathrm{KN} . \mathrm{m})$ & 50,22 & 13,29 \\
\hline
\end{tabular}

Tabela 3. Comparação dos esforços solicitados entre as duas estruturas, considerando peso próprio e sobrecarga permanente

A tabela a seguir relaciona a estrutura constituinte de nove vigas longarinas principais com uma estrutura similar, onde foram retiradas 4 vigas longarinas, levando em consideração momento fletor, esforço cortante e esforço torçor, para o carregamento da carga móvel.

\begin{tabular}{|c|c|c|}
\hline \multicolumn{3}{|c|}{ VALORES CONSIDERANDO A CARGA MÓVEL } \\
\hline & Ponte com 9 longarinas & Ponte com 5 longarinas \\
\hline Momentos fletores (KN.m) & 1858,99 & 2778,00 \\
\hline Esforços cortantes $(\mathrm{KN})$ & 237,85 & 361,80 \\
\hline Esforço de torção $(\mathrm{KN} . \mathrm{m})$ & 56,70 & 18,79 \\
\hline
\end{tabular}

Tabela 4.Comparação dos esforços solicitados, entre as duas estruturas, considerando carga móvel

A tabela abaixo relaciona os valores de frequência em $\mathrm{Hz}$ da estrutura com nove e com cinco vigas longarinas.

\begin{tabular}{|c|c|c|}
\hline Modo & \multicolumn{2}{|c|}{ Frequência (Hz) } \\
\hline & Ponte com 9 longarinas & Ponte com 5 longarinas \\
\hline 1 & 3,20914 & 2,68729 \\
\hline 2 & 3,37109 & 2,99636 \\
\hline 3 & 4,20523 & 3,97972 \\
\hline 4 & 4,69027 & 5,01218 \\
\hline 5 & 5,9675 & 6,28708 \\
\hline
\end{tabular}


Comparando-se os modelos com 9 ou 5 longarinas, verificou-se o aumento considerável do momento fletor e do esforço cortante quando se diminuiu a quantidade de vigas longarinas principais, porém ocorreu uma diminuição no esforço torçor.

A ponte com 5 longarinas obteve uma oscilação bem maior nos valores de frequências naturais, que quando muito baixas são perigosas para a estrutura, pois aumenta a chance de ressonância, que é o fenômeno que acontece quando um sistema físico recebe energia por meio de excitações de frequência igual a uma de suas frequências naturais de vibração. Assim, o sistema físico passa a vibrar com amplitudes cada vez maiores.

\section{CONCLUSÕES}

O modelo computacional através do software representou bem o comportamento da estrutura, pois mostrou o funcionamento conjunto de todas as partes da mesma. Entretanto, é um modelo mais trabalhoso de ser elaborado e complexo em termos da interpretação de resultados. No entanto, em se tratando de verificação de projeto e/ou de estrutura existente, sua utilização parece ser indicada. Aconselha-se para estudos futuros a análise da laje, afim de saber o seu comportamento após a diminuição do número de vigas e/ou o estudo do consumo de materiais entre as duas estruturas. 


\section{REFERÊNCIAS}

ABNT NBR 7187. Projeto de pontes de concreto armado e de concreto protendido Procedimento. Rio de Janeiro, 2003.

ABNT NBR 7188. Carga móvel em ponte rodoviária e passarela de pedestre. Rio de Janeiro, 1984.

ABNT NBR 6118. Projeto de estruturas de concreto - Procedimento. Rio de Janeiro, 2003. ABNT NBR 6123. Forças devidas ao vento em edificações - Procedimento. Rio de Janeiro, 1988.

ABNT NBR 7188. Carga móvel em ponte rodoviária e passarela de pedestre Procedimento. Rio de Janeiro, 1984.

ABNT NBR 7189. Cargas móveis para projeto estrutural de obras ferroviárias Procedimento. Rio de Janeiro, 1985.

ABNT NBR 8681. Ações e segurança nas estruturas - Procedimento. Rio de Janeiro, 2003.

ABNT NBR 10839. Execução de obras de arte especiais em concreto armado e concreto protendido - Procedimento. Rio de Janeiro, 1989.

ABNT NBR 12655. Concreto - Preparo, controle e recebimento. Rio de Janeiro, 1996.

DNER - Departamento Nacional de Estradas de Rodagem. Manual de Projeto de Obrasde-arte Especiais. Rio de Janeiro. Diretoria de Desenvolvimento Tecnológico, 1996.

FUSCO, Pericles Brasiliense. Estruturas de concreto: Solicitações Normais, Estados Limites Últimos. 1.ed. Rio de Janeiro: LTC - Livros Técnicos e Científicos Editora S.A. 1981.

PFEIL, Walter. Pontes em concreto armado. 1. ed. Rio de Janeiro: Livros Técnicos e Científicos Editora S.A. 1979

PFEIL, WALTER. Concreto protendido: processos construtivos e perdas de protensão. 2 ed. Rio de Janeiro: Livros Técnicos e Científicos, 1983. 325 p. 